\title{
Papers
}

Editorial by Clauw and p 1370

\section{Incidence of cancer among UK Gulf war veterans: cohort study}

\author{
Gary J Macfarlane, Anne-Marie Biggs, Noreen Maconochie, Matthew Hotopf, Patricia Doyle, Mark Lunt
}

\begin{abstract}
Objectives To determine whether incidence rates of cancer are higher in UK service personnel who were deployed in the Gulf war than in those not deployed and whether any increased risk of cancer is related to self reported exposures to potentially hazardous material during the period of deployment.

Design A cohort study with follow up from 1 April 1991 (the end of the Gulf war) to 31 July 2002.

Participants 51721 Gulf war veterans and 50755 service personnel matched for age, sex, rank, service, and level of fitness who were not deployed in the Gulf (the Era cohort).

Main outcome measures Incident cancers, identified on the NHS central register.

Results There were 270 incident cancers among the Gulf cohort and 269 among the Era cohort (incidence rate ratio $0.99,95 \%$ confidence interval 0.83 to 1.17 ). There was no excess in site specific cancers among the Gulf cohort. Adjustment for lifestyle factors (smoking and alcohol consumption) did not alter these results. In the Gulf cohort, risk of cancer was not related to multiple vaccinations or exposure to pesticides or depleted uranium during deployment.

Conclusion There is no current excess risk of cancer overall nor of site specific cancers in Gulf war veterans. Specific exposures during deployment have not resulted in a subsequent increased risk of cancer. The long latent period for cancer, however, necessitates the continued follow up of these cohorts.
\end{abstract}

\section{Introduction}

Studies among UK veterans of the Gulf war have shown an excess of self reported morbidity compared with that seen in members of the armed forces who were serving at the time of the Gulf war (1991) and were fit for active service but were not deployed. ${ }^{12}$ The excess is evident across all types of morbidity, but there are no unusual clusters of symptoms. ${ }^{23}$ The symptoms most commonly reported are non-specific, such as fatigue, stiffness, sleep disturbance, sudden changes of mood, irritability, and poor memory.

There has been concern about a possible link between service in the Gulf and an increased risk of cancer, particularly in relation to personnel who were exposed to depleted uranium. A review of the evidence, however, concluded that, except in extreme circumstances, any excess risk is likely to be small. ${ }^{4}$ A US study among a sample of Gulf war veterans found an excess of testicular cancer in the short term, ${ }^{5}$ while a study of admissions to hospital among US Gulf War veterans found excess admissions for cancers (mostly benign) during 1991. Mortality studies of US ${ }^{6}$ and UK veterans, ${ }^{7}$ however, found no increased risk of death from cancer.
We examined whether UK Gulf veterans have experienced increased incidence rates of cancer in the 11 years since the end of the war compared with service personnel not deployed; whether any excess risk, if found, could be explained by the possible confounding effects of lifestyle factors (such as cigarette smoking and alcohol consumption); and whether risk of cancer is related to self reported exposures to potentially hazardous material during the period of deployment.

\section{Methods}

We carried out a cohort study of all UK armed forces personnel who served in the Gulf area sometime between September 1990 and June 1991 (the "Gulf" cohort). Specific details of the "Gulf area" as defined for this study have previously been described. ${ }^{7} \mathrm{~A}$ comparison group of the same size was randomly selected from members of the armed forces who were in service on 1 January 1991 but who were not deployed to the Gulf area (the "Era" cohort). This comparison group was stratified to match the Gulf cohort on age, sex, service branch and rank, and (for the army and air force) level of fitness for active service. Staff from the Gulf Veterans' Illnesses Unit of the Ministry of Defence identified Gulf cohort members and selected Era cohort members.

Details of all members of the two cohorts were sent to National Statistics for identification on the NHS central register. This register was established in 1939 and contains an entry for everyone in the United Kingdom who has ever been registered with a general practitioner and all people born in, or who have immigrated to, the United Kingdom. The register contains information on cancers diagnosed, including date of diagnosis and information on site of cancer, coded according to ICD-10 (international classification of diseases, 10th revision). Information is also available (with dates) on deaths and on people emigrating from the United Kingdom.

Over $96 \%$ of members of both cohorts were identified and "flagged" on the NHS central register and are included in the current analysis. We included information on the first diagnoses of malignant cancer (ICD-10 codes C00-C95) registered on the NHS central register with date of diagnosis before 31 July 2002. We calculated person years at risk for cancer from 1 April 1991 (the nominal end of the Gulf War) until the earliest of either date of emigration from the United Kingdom, date of death, date of first diagnosis of cancer, or 31 July 2002.

We analysed the data with a Cox proportional hazards model with adjustment for sex, age group, service branch and rank, and a comparison between Gulf and Era veterans, that is, expressed as an incidence rate ratio (equivalent to the hazard ratio) with $95 \%$ confidence interval. To determine whether the incidence rate ratio changed with time, it was calculated separately for the periods before (inclusive) and after December 1997 (this date 
Table 1 Morbidity surveys among Gulf War veterans and service personnel who were not deployed in the Gulf (Era cohort)

\begin{tabular}{|c|c|c|c|c|}
\hline \multirow[b]{2}{*}{ Survey } & \multirow[b]{2}{*}{ Reference } & \multirow[b]{2}{*}{ Date of survey } & \multicolumn{2}{|c|}{ No of participants } \\
\hline & & & Gulf & Era cohort \\
\hline 1 & Unwin, $1999^{1}$ & Sept 1997 - Nov 1998 & 2735 & 2422 \\
\hline 2 & Cherry, $2001^{2}$ & Dec 1997 - Sep 1999 & 8081 & 3935 \\
\hline 3 & Maconochie, $2003^{8}$ & Aug 1998 - Mar 2001 & 25084 & 19003 \\
\hline
\end{tabular}

Table 2 Demographic and military characteristics of cohort members eligible for follow up according to whether they served in the Gulf. Figures are numbers (percentages) of members

\begin{tabular}{|c|c|c|c|}
\hline & Gulf cohort ( $n=51721$ ) & Era cohort ( $n=50755)$ & Total \\
\hline Men & $50637(98)$ & $49685(98)$ & $100322(98)$ \\
\hline Women & $1084(2)$ & $1070(2)$ & $2154(2)$ \\
\hline \multicolumn{4}{|l|}{ Age (years): } \\
\hline$<20$ & $6165(12)$ & $6038(12)$ & $12203(12)$ \\
\hline $20-24$ & $18390(35)$ & $17880(35)$ & $36270(35)$ \\
\hline $25-29$ & $12463(24)$ & $12287(24)$ & $24750(24)$ \\
\hline $30-34$ & 7648 (15) & 7569 (15) & $15217(15)$ \\
\hline $35-39$ & $4197(8)$ & $4173(8)$ & $8370(8)$ \\
\hline$>39$ & $2858(6)$ & $2808(6)$ & $5666(6)$ \\
\hline \multicolumn{4}{|l|}{ Rank: } \\
\hline Officer & 5779 (11) & $5626(11)$ & 11405 (11) \\
\hline Other ranks & $45942(89)$ & $45129(89)$ & 91071 (89) \\
\hline \multicolumn{4}{|l|}{ Service branch: } \\
\hline Army & $36272(70)$ & $35324(70)$ & $71596(70)$ \\
\hline Navy & $5738(11)$ & $5706(11)$ & $11444(11)$ \\
\hline Air Force & 9711 (19) & 9725 (19) & 19436 (19) \\
\hline
\end{tabular}

Table 3 Occurrence of cancer among cohort members according to whether they served in the Gulf: demographic and military characteristics

\begin{tabular}{|c|c|c|c|}
\hline & Gulf cohort ( $n=51721$ ) & Era cohort ( $n=50755)$ & Incidence rate ratio $(95 \% \mathrm{Cl})$ \\
\hline All cancers & 270 & 269 & $0.99(0.83$ to 1.17$)$ \\
\hline Men & 257 & 256 & $0.99(0.83$ to 1.17$)$ \\
\hline Women & 13 & 13 & 0.98 (0.47 to 2.12$)$ \\
\hline \multicolumn{4}{|l|}{ Age (years): } \\
\hline$<20$ & 11 & 12 & $0.90(0.40$ to 2.03$)$ \\
\hline $20-24$ & 39 & 48 & 0.79 (0.52 to 1.21$)$ \\
\hline $25-29$ & 46 & 41 & $1.11(0.73$ to 1.69$)$ \\
\hline $30-34$ & 41 & 40 & $1.02(0.66$ to 1.57$)$ \\
\hline $35-39$ & 52 & 38 & 1.37 (0.90 to 2.08$)$ \\
\hline$>39$ & 81 & 90 & $0.89(0.66$ to 1.20$)$ \\
\hline \multicolumn{4}{|l|}{ Rank: } \\
\hline Officer & 77 & 64 & 1.18 (0.84 to 1.64$)$ \\
\hline Other ranks & 193 & 205 & 0.93 (0.76 to 1.13$)$ \\
\hline \multicolumn{4}{|l|}{ Service branch: } \\
\hline Army & 170 & 175 & $0.95(0.77$ to 1.17$)$ \\
\hline Navy & 38 & 26 & $1.46(0.88$ to 2.40$)$ \\
\hline Air Force & 62 & 68 & $0.92(0.65$ to 1.29$)$ \\
\hline
\end{tabular}

was chosen to give the same number of incident cancers in the two time periods).

The Gulf and Era cohorts also acted as a sampling frame for three morbidity surveys conducted between 1997-2001. ${ }^{128}$ The first two surveys, both surveys of general health, drew random samples from each of the cohorts (using non-overlapping samples) while the third survey, a study of reproductive and child health, included all people in both cohorts (table 1). These studies collected information in a consistent way about tobacco smoking (current smoker, previous smoker, never smoker), alcohol intake at the time of the survey, and, in the Gulf cohort, exposures to potentially hazardous material during service in the Gulf. We used information from the third study if possible $(\mathrm{n}=40853)$ and otherwise from studies 1 and $2(\mathrm{n}=8494)$. Among people participating in at least one of these three morbidity surveys, we compared the incidence of cancer between Gulf and Era cohort members, additionally adjusting for the effects of tobacco smoking and alcohol intake using a Cox proportional hazards model. Secondly, we compared cancer incidence according to certain exposures during the time in the Gulf. Effects are again reported as incidence rate ratios and 95\% confidence intervals.

\section{Results}

Both cohorts initially comprised 53462 members. We excluded from follow up 44 from the Gulf cohort and 10 from the Era cohort who had died, two from each cohort who had emigrated, 29 from the Gulf cohort and 52 from the Era cohort who had had cancer diagnosed before 1 April 1991, and five in each cohort who were recorded as having had cancer diagnosed but without a date. A further 3987 people (1653 Gulf and 2334 Era) could not be identified on the NHS central register. Further information from the Ministry of Defence resulted in the exclu- 


\begin{tabular}{|c|c|c|c|c|}
\hline Cancer type & (ICD-10 code) & Gulf & Era & Incidence rate ratio \\
\hline All cancers & C00-97 & 268 & 265 & 0.98 (0.82 to 1.18$)$ \\
\hline All excluding non-melanoma skin cancer & All except C44 & 213 & 215 & $0.97(0.81$ to 1.18$)$ \\
\hline Oral cavity & $\mathrm{COO}-14$ & 9 & 8 & 1.11 (0.43 to 2.87$)$ \\
\hline Upper digestive tract & C15-17 & 9 & 6 & $1.47(0.53$ to 4.14$)$ \\
\hline Lower digestive tract & C18-21 & 13 & 18 & $0.71(0.35$ to 1.45$)$ \\
\hline Bronchus, lung, and trachea & C33-34 & 14 & 18 & $0.76(0.38$ to 1.54$)$ \\
\hline Malignant melanoma skin & C43 & 14 & 10 & $1.38(0.61$ to 3.10$)$ \\
\hline Other skin & C44 & 55 & 50 & $1.08(0.74$ to 1.59$)$ \\
\hline Breast & C50 & 6 & 10 & 0.59 (0.21 to 1.62$)$ \\
\hline Prostate & C61 & 7 & 6 & 1.15 (0.39 to 3.41$)$ \\
\hline Testis & C62 & 39 & 46 & 0.83 (0.54 to 1.28$)$ \\
\hline Urinary tract & C64-8 & 13 & 9 & 1.42 (0.61 to 3.32$)$ \\
\hline Central nervous system & C69-72 & 21 & 25 & 0.83 (0.46 to 1.48$)$ \\
\hline Lymphoid and haematopoietic & C81-96 & 45 & 34 & 1.30 (0.83 to 2.03$)$ \\
\hline All other sites & Various $^{*}$ & 23 & 25 & 0.90 (0.51 to 1.59$)$ \\
\hline ICD code unavailable & & 2 & 4 & \\
\hline
\end{tabular}

${ }^{*} \mathrm{C} 22-32,35-42,45-49,51-60,63,73-80,97$.

Table 5 Occurrence of site specific cancer among cohort members according to whether they served in the Gulf: adjusted for smoking and alcohol consumption

\begin{tabular}{|c|c|c|c|c|c|}
\hline \multirow[b]{2}{*}{ Cancer type } & \multirow[b]{2}{*}{ ICD-10 code } & \multirow[b]{2}{*}{ Gulf ( $\mathrm{n}=28518$ ) } & \multirow[b]{2}{*}{ Era $(n=20829)$} & \multicolumn{2}{|c|}{ Incidence rate ratio } \\
\hline & & & & Unadjusted & Adjusted \\
\hline All cancers & $\mathrm{CO0}-97$ & 144 & 95 & $1.11(0.86$ to 1.44$)$ & $1.12(0.86$ to 1.45$)$ \\
\hline $\begin{array}{l}\text { All excluding non-melanoma skin } \\
\text { cancer }\end{array}$ & All except C44 & 109 & 75 & $1.06(0.79$ to 1.43$)$ & 1.07 (0.79 to 1.43$)$ \\
\hline Oral cavity & $\mathrm{COO}-14$ & 4 & 5 & 0.59 (0.16 to 2.18$)$ & $0.58(0.16$ to 2.16$)$ \\
\hline Upper digestive tract & C15-17 & 2 & 2 & $0.73(0.10$ to 5.19$)$ & $0.69(0.10$ to 4.93$)$ \\
\hline Lower digestive tract & C18-21 & 6 & 6 & 0.73 (0.24 to 2.27$)$ & 0.73 (0.24 to 2.27$)$ \\
\hline Bronchus, lung, and trachea & C33-34 & 3 & 5 & $0.49(0.10$ to 1.84$)$ & $0.41(0.10$ to 1.73$)$ \\
\hline Malignant melanoma skin & $\mathrm{C} 43$ & 10 & 5 & $1.46(0.50$ to 4.28$)$ & $1.50(0.51$ to 4.40$)$ \\
\hline Other skin & C44 & 35 & 20 & 1.28 (0.74 to 2.22$)$ & 1.30 (0.75 to 2.26$)$ \\
\hline Breast & C50 & 5 & 4 & 0.91 (0.25 to 3.41$)$ & 0.98 (0.26 to 3.64$)$ \\
\hline Prostate & C61 & 4 & 3 & 0.98 (0.22 to 4.36$)$ & 1.03 (0.23 to 4.62$)$ \\
\hline Testis & $\mathrm{C} 62$ & 24 & 15 & 1.17 (0.61 to 2.23$)$ & 1.17 (0.61 to 2.23$)$ \\
\hline Urinary tract & C64-8 & 7 & 4 & $1.28(0.37$ to 4.37$)$ & $1.29(0.38$ to 4.41$)$ \\
\hline Central nervous system & C69-72 & 12 & 8 & $1.10(0.45$ to 2.68$)$ & 1.08 (0.44 to 2.65$)$ \\
\hline Lymphoid and haematopoietic & C81-96 & 24 & 11 & 1.60 (0.78 to 3.26$)$ & 1.60 (0.79 to 3.28$)$ \\
\hline All other sites & Various* & 8 & 7 & $0.84(0.30$ to 2.31$)$ & 0.84 (0.30 to 2.32) \\
\hline ICD code unavailable & & 2 & 0 & & \\
\hline
\end{tabular}

${ }^{*}$ C22-32, 35-42, 45-49, 51-60, 63, 73-80, 97.

sion of eight from the Gulf cohort and 304 from the Era cohort who did not meet the entry criteria. Table 2 gives the demographic characteristics of the 51721 and 50755 cohort members who were followed up.

During follow up cancer was diagnosed in 270 Gulf veterans and 269 Era veterans (incidence rate ratio $0.99,95 \%$ confidence interval 0.83 to 1.17 ) (table 3). There was no large or significant excess of cancers in either men or women or in any service branch, rank, or age group. The incidence rate ratio did not differ significantly between the period up to and including 1997 (1.04, 0.82 to 1.32$)$ and the later period $(0.93,0.74$ to 1.19$)$. After exclusion of non-melanoma skin cancers and cancers for which site information was unavailable, there were a total of 213 and 215 Gulf and Era veterans, respectively, in whom cancer was diagnosed (0.97, 0.81 to 1.18 ) (table 4 ).

A comparison of incidence rates of cancer among subgroups of cohort members who participated in one of the morbidity surveys and provided information on smoking and alcohol similarly showed no significant excess of cancers among the Gulf veterans $(1.11,0.86$ to 1.44$)$. This incidence rate ratio was slightly, but not significantly, higher than that among cohort members who did not take part in one of the morbidity surveys $(0.95,0.75$ to 1.19). Among cohort members who did participate in a morbidity survey, the incidence rate ratio did not change (1.12, 0.86 to 1.45) after we adjusted for smoking status (current, past, never smoker) and for the usual intake of alcohol at the time they completed the questionnaire (table 5). This additional adjustment for tobacco and alcohol intake also resulted in little or no change in any of the risks for site specific cancers (table 5). Finally, among the Gulf veterans who participated in at least one of the morbidity surveys we examined the incidence of cancer with respect to some of the exposures reported during deployment to the Gulf. Neither exposure to pesticides (through handling, personal use, or sprayed accommodation) nor multiple vaccination against anthrax, plague, and pertussis nor reported exposure to depleted uranium was associated with any subsequent significant excess risk of cancer, either overall (table 6) or for site specific cancers (data not shown).

\section{Discussion}

Our study of 102476 veterans has shown that the incidence of cancer in those who served in the Gulf was similar to that in veterans who were fit for active service but were not deployed. This 
Table 6 Risk of any cancer by exposure agent among cohort members who served in the Gulf

\begin{tabular}{|c|c|c|c|c|c|}
\hline \multirow[b]{2}{*}{ Exposure agent } & \multicolumn{2}{|c|}{ Not exposed } & \multicolumn{2}{|c|}{ Exposed } & \multirow[b]{2}{*}{ Incidence rate ratio $(95 \% \mathrm{Cl})$} \\
\hline & Total & Cancers & Total & Cancers & \\
\hline $\begin{array}{l}\text { Multiple vaccination (anthrax, plague, } \\
\text { pertussis) }\end{array}$ & 21313 & 107 & 7205 & 39 & $1.08(0.75$ to 1.56$)$ \\
\hline Used personal pesticides or insecticides & 13125 & 82 & 15393 & 64 & 0.66 (0.48 to 0.92$)$ \\
\hline Handled pesticides & 26467 & 134 & 2051 & 12 & 1.16 (0.64 to 2.09$)$ \\
\hline Living quarters treated with pesticides & 22251 & 115 & 6267 & 31 & 0.96 (0.64 to 1.42$)$ \\
\hline Depleted uranium & 26426 & 139 & 2092 & 7 & 0.63 (0.30 to 1.36$)$ \\
\hline
\end{tabular}

\section{What is already known on this topic}

Veterans of the 1990-1 Gulf war have an excess of self reported symptoms

Their mortality experience (including cancer mortality) is similar to that seen in military personnel who were serving at the same time but who were not deployed in the Gulf

\section{What this study adds}

Incidence of and mortality from cancer in Gulf War veterans is almost identical to that seen in veterans who were not deployed in the Gulf

This comparison takes account of lifestyle factors (smoking and alcohol consumption), which are known to influence cancer risk

The risk of cancer was no higher in Gulf war veterans who reported exposure to specific substances such as depleted uranium or pesticides

result did not change when we took into account the effects of lifestyle (smoking and alcohol consumption) among a subgroup who participated in one of the UK morbidity surveys. In this subgroup there was no significant excess risk of cancer associated with reported exposure to pesticides, multiple vaccination against anthrax, plague and pertussis, or exposure to depleted uranium.

There are several methodological considerations regarding the current study. Firstly, though we excluded the small number of cohort members who could not be traced through the NHS central register, some information was available on diagnoses of cancer in these people from alternative sources. Among them the number of cancers was higher in the Era cohort $(n=11)$ than in the Gulf cohort $(n=3)$. Secondly, information on lifestyle habits was obtained only at the time of the morbidity surveys, $6-10$ years after the Gulf war. These data show that the proportion who were current smokers and the amount of alcohol drunk in a week were similar in the two cohorts, ${ }^{12}$ and thus the estimates of rate ratios are little changed with adjustment for these factors. We will have underestimated the relative risk of cancer in Gulf war veterans only if they habitually smoked less or drank less alcohol and had recently increased consumption (or vice versa in relation to Era veterans). Neither seems plausible. Finally, the "exposures" reported at the time of the Gulf are, in the absence of any objective measure of individual exposure, based on self report. The concern about self reported exposures is that people who develop an adverse health outcome may differentially recall past events. This is most likely to result in ill people over-reporting past exposures and well people under-reporting (that is, forgetting) them. With either scenario, the observed effect of an exposure on health will be overestimated and there- fore this could not explain our failure to detect true adverse effects of any of these exposures if they were to exist.

Relatively little information has been published on cancers among Gulf war veterans. The mortality study among the same group of UK Gulf and Era veterans showed only a small non-significant increased risk of death from cancer nine years after the end of the conflict (mortality rate ratio $1.11,0.73$ to 1.67). ${ }^{7}$ A mortality study among US veterans also failed to show an increased risk of death from cancer seven years after the end of the conflict $(0.90,0.81$ to 1.01 , for men; $1.11,0.78$ to 1.57 for women). ${ }^{6}$ In the US study there was no increased risk of death from cancer among Gulf War veterans who were potentially exposed to nerve gas as a result of US troops exploding abandoned Iraqi munitions $(0.95,0.69$ to 1.30$)$. An early report of an increased risk of testicular cancer in the period immediately after deployment was no longer evident on further follow up. It was concluded that the original observed excess was because healthy serviceman were selected for deployment and care was deferred during deployment. ${ }^{5}$

In summary, our results confirm that there is no overall increase in incidence of or mortality from cancer among UK Gulf veterans. Neither was the incidence of cancer higher among those veterans who reported specific exposures during their deployment. Although this study should provide some reassurance of a lack of association between deployment to the Gulf and increased risk of cancer, the long latent period for cancer requires that these cohorts should continue to be followed up and their experience of cancer monitored.

We acknowledge the contribution of other researchers to the conduct of the United Kingdom morbidity surveys and mortality study: David Baxter, Nicola Cherry, William Coker, Francis Creed, Anthony David, Graham Davies, Graham Dunn, Susan Ferry, Lisa Hull, Khalida Ismail, Samantha Lewis, Ian Palmer, Margo Pelerin, Sue Prior, Patrick Sampson, Alan J Silman, Joanne Smedley, Stewart Taylor, Catherine Unwin, and Simon Wessely. We thank Nick Blatchley (Ministry of Defence), who identified the study cohorts, and staff from National Statistics in Southport, who traced them on the NHS central register.

Contributors: GJM planned the study, and GJM, NM, PD, and MH were involved in the collection of data in the morbidity surveys. A-MB and ML conducted the data analysis. GJM drafted the manuscript, which was then revised by all authors. GJM, A-MB, and ML are guarantors.

Funding: Ministry of Defence.

Competing interests: None declared.

Ethical approval: University of Manchester Committee on the Ethics of Research on Human Beings.

1 Unwin C, Blatchley N, Coker W, Ferry S, Hotopf M, Hull L, et al. Health of UK servicemen who served in Persian Gulf War. Lancet 1999;353:169-78.

2 Cherry N, Creed F, Silman A, Dunn G, Baxter D, Smedley J, et al. Health and exposure of United Kingdom Gulf war veterans. Part 1: The pattern and extent of ill-health Occup Environ Med 2001;58:291-8.

3 Everitt B, Ismail K, David AS, Wessely S. Searching for a Gulf War syndrome using cluster analysis. Psychol Med 2002;32:1371-8. 4 Royal Society Report. The health effects of depleted uranium munitions Part 1. London:

Knoke JD, Gray GC, Garland FC. Testicular cancer and Persian Gulf War service. EpiKnoke JD, Gray GC, Gar
demiology 1998;9:648-53.

Kamiology 1998;9:648-53. follow-up. Am J Epidemiol 2001;154:399-405. 
7 Macfarlane GJ, Thomas E, Cherry N. Mortality among UK Gulf War Veterans. Lancet 2000;356:17-21.

8 Maconochie N, Doyle P, Davies G, Lewis S, Pelerin M, Prior S, et al. The study of reproductive outcome and the health of offspring of UK veterans of the Gulf war: method and description of the study population. BMC Public Health 2003;3:4.

(Accepted 7 October 2003)

bmj.com 2003;327:1373

Unit of Chronic Disease Epidemiology, School of Epidemiology and Health Sciences, University of Manchester, Manchester M13 9PT

Gary J Macfarlane professor of epidemiology

Anne-Marie Biggs research associate
London School of Hygiene and Tropical Medicine, University of London, London WC1E 7HT

Noreen Maconochie senior lecturer in epidemiology and statistics

Patricia Doyle reader in epidemiology

Gulf War Illnesses Research Unit, Department of Psychological Medicine, Guy's, King's, and St Thomas's School of Medicine, London SE5 8AZ

Matthew Hotopf reader in psychological medicine

Arthritis Research Campaign Epidemiology Unit, School of Epidemiology and Health Sciences, University of Manchester

Mark Lunt research fellow

Correspondence to: G J Macfarlane

G.Macfarlane@man.ac.uk 